\title{
Relação família-escola: práticas educativas utilizadas por pais e professores
}

\author{
Luiza Maria de Oliveira Braga Silveira \\ Adriana Wagner
}

\section{Resumo}

Este estudo analisa as continuidades e descontinuidades na relação família-escola frente aos problemas de comportamento da criança, investigando a utilização e as percepções sobre as práticas educativas de pais e professores em ambos os contextos, bem como a existência de ações conjuntas. Participaram do estudo 4 progenitores e 4 professoras de escolas privadas de Porto Alegre, respondendo, cada um deles, a duas entrevistas cujos dados sofreram análise de conteúdo. Os resultados apontaram heterogeneidade das práticas educativas parentais e diferentes níveis de conhecimento entre os participantes acerca das práticas utilizadas, revelando fronteiras rígidas entre a família e a escola. Identificou-se a supremacia do saber das professoras sobre os pais, reforçada pelo fato das atitudes conjuntas enfocarem o caráter curativo e orientador da escola sobre a família. A discussão dos dados propõe alternativas para uma intervenção conjunta família-escola frente aos problemas de comportamento das crianças.

Palavras-chave: Relações pais-escola, práticas de criação infantil, criança-problema.

\section{Family-school relationship: parents and teacher's educative practices}

\begin{abstract}
This article aims to analyze the family-school relationship and its continuity and discontinuity towards child behavior problems. We investigate the perception and use of child-rearing practices by parents and teachers, within both contexts. We also investigate whether there were some planned joint activities towards child behavior problems. Four parents and four teachers from Porto Alegre private schools have participated in this study by answering two interviews. These interviews were analyzed according to their content. The results indicated heterogeneity in the parents' educative practices, distinct levels of knowledge about educative practices among the participant subjects. They reveal a clear boundary between family and school. It was identified the supremacy of teacher's knowledge over parents' knowledge. This was reinforced by the fact that joint activities focused on the family orientation by the school. The results were discussed and we proposed alternatives to a family-school integrative intervention towards child behavior problems.
\end{abstract}

Keywords: Parent-school relationship, child-rearing practices, problem children.

\section{Relación familia-escuela: prácticas educativas usadas por padres y profesores}

\begin{abstract}
Resumen
Este estudio analiza las continuidades y discontinuidades en la relación familia-escuela frente a los problemas de comportamiento del niño, investigando la utilización y las percepciones sobre las prácticas educativas de padres y profesores en ambos contextos; así como la existencia de acciones conjuntas. Participaron del estudio cuatro progenitores y cuatro profesoras de escuelas privadas de Porto Alegre, respondiendo cada uno de ellos a dos entrevistas; cuyos datos fueron sometidos a Análisis de Contenido. Los resultados indicaron heterogeneidad de las prácticas educativas parentales y diferentes niveles de conocimiento entre los participantes acerca de las prácticas utilizadas, revelando fronteras rígidas entre la familia y la escuela. Se identificó la supremacía del saber de las profesoras sobre los padres, reforzada por el hecho de que las actitudes conjuntas enfocan el carácter curativo y orientador de la escuela sobre la familia. La discusión de los datos propone alternativas para una intervención conjunta familia-escuela frente a los problemas de comportamiento de los niños.
\end{abstract}

Palabras-clave: Relaciones padre-escuela, prácticas de crianza infantil, niño problema. 


\section{Introdução}

Desde o surgimento da escola como instituição social e sistema de educação formal, suas raízes encontram-se entrelaçadas à família, embora sua concepção existisse desde a Paideia. No entanto, situa-se o surgimento da escola como formalização e institucionalização do ensino a partir da Idade Moderna (Silveira, 2003), estabelecendo-se como sistema de ensino formal para cumprir o que a Igreja já não dava conta plenamente (Dabas, 2005).

A modernidade delegou ao saber um lugar de excelência, tornando-o exclusividade dos bancos acadêmicos. As relações tornaram-se marcadas pela lógica do saber, pontuando diferenças intelectuais, hierarquizando os sujeitos e tendo um propósito de universalização (Dabas, 2005; Carvalho, 2004; Harvey, 1989; Viana, 2005).

Durante estes anos, construiu-se a ideia de que a escola é responsável pela educação formal das crianças e adolescentes, enquanto a família o é pela educação informal. Tal ideia parece ser sustentada até hoje por crenças e ideais que mantêm distantes e dissociados os âmbitos das relações e funções de ambos os sistemas (Chechia \& Andrade, 2005; Oliveira, 2002; Viana, 2005). Mesmo com tantas mudanças políticas, sociais e relacionais, a escola parece ainda distanciar as famílias e buscar conservar seu domínio sobre o saber através da crença de omissão dos pais (Viana, 2005).

A relação família-escola pode ser analisada tanto sob um prisma sociológico, como psicológico, conforme Oliveira (2002). Numa perspectiva sociológica, destaca-se o caráter socializador desta relação e as diferenças sociais e culturais entre ambas. Já o prisma psicológico parte da importância das primeiras relações vividas na família (socialização primária) e suas implicações no processo escolar (socialização secundária). Por isso, entende-se que muitos processos, a partir desse olhar, pressupõem como um objetivo da escola também educar as famílias, fornecendo informações sobre o desenvolvimento e educação infantil e atendimento psicológico. Tais ideias ressaltam o caráter curativo de um sistema sobre o outro.

Tal análise sob o prisma psicológico concede à família, ainda, o valor explicativo dos problemas das crianças e adolescentes. Assim, inicia-se também uma nova matriz nas relações professores-pais/família-escola; na qual se torna importante que professores conheçam e tenham informações a respeito da vida familiar de seus alunos. A partir disso, aceita-se que os professores orientem os pais a respeito da educação das crianças e de sua formação psíquica (Dowling, 1996; Oliveira, 2002).

A comunicação e a troca de informações entre a família e a escola parece ser objeto de controvérsias, pois são avaliadas tanto de forma positiva como negativa. A intensa circulação de conceitos, métodos, valores e ideais entre as instituições podem gerar uma confusão quanto a seus objetivos (pulverizando-os, modificando-os, afastandoos, desconstruindo-os etc.), sendo utilizada, por vezes, como intromissão na vida das famílias (Oliveira, 2002). Esta crença tende a se traduzir em atitudes paternalistas e "de especialistas", não favorecendo as relações família-escola (Vila, 2003).

De uma forma positiva, a existência de tais canais de comunicação e de participação entre a vida familiar e escolar pode também favorecer o desenvolvimento infantil e da relação família-escola. Estudos recentes têm reiterado a importância da comunicação e da participação entre os sistemas como uma importante fonte de retroalimentação (ou feedback) permanente, promovendo a transição da criança entre um sistema e outro e assim seu crescimento (Carvalho, 2004; Chechia \& Andrade, 2005; Ditrano \& Silveirstein, 2006; Johnsons, Pugach, \& Hawkins, 2004; Viana, 2005; Vila, 2003).

Nesse sentido, partindo do pressuposto de que tanto pais como professores ocupam lugares distintos e cumprem funções diferentes (Chechia \& Andrade, 2005; Collins, Maccoby, Steinberg, Hetherington, \& Bornstein, 2000), considera-se as interações entre eles e a complementaridade de suas funções na educação de crianças algo positivo. Entretanto, faz-se necessário guardar as suas convergências e pontuar as suas responsabilidades específicas, promovendo novas reflexões junto à sociedade, às instituições e aos sujeitos.

Questionamos então: a forma como a família e a escola buscam atingir seus objetivos educativos revela continuidades ou descontinuidades entre elas? Essas continuidades ou descontinuidades podem ser consideradas indicadores de como a escola e a família se relacionam e interagem?

Entendemos que uma das formas de visualizarmos esta interação é através das práticas educativas, chamadas também de práticas de socialização (Belsky, Jaffee, Hsieh \& Silva, 2001; Hoffman, 1994; Viana, 2005). Dessa forma, o conhecimento dos agentes educativos (pais ou professores) a respeito das práticas utilizadas no outro sistema pode sinalizar o nível de interação das instituições e características dessa relação.

De forma geral, as práticas educativas buscam modificar comportamentos inadequados às regras e padrões morais e sociais, assim como promover os que são considerados adequados e desejados pelos pais/ educadores (Alvarenga \& Piccinini, 2001; Bolsoni-Silva \& Marturano, 2002; Ferreira \& Marturano, 2002; Goldwater \& Nutt, 1999). As práticas educativas, conforme modelo proposto por Hoffman $(1975,1994)$ são classificadas em dois tipos: indutivas ou coercitivas. As práticas educativas coercitivas referem-se especialmente ao caráter punitivo das (re)ações educativas, reduzindo a possibilidade de a criança compreender a necessidade de modificar seu comportamento e as consequências de suas ações. De forma contrária, as práticas educativas indutivas privilegiam as explicações lógicas sobre a consequência do comportamento para si e para os outros, destacando as implicações desses comportamentos e favorecendo a empatia (Alvarenga, 2000; Ceballos \& Rodrigo, 2003; Hoffman, 1994). As práticas educativas utilizadas na escola também podem ser classificadas como punitivas (coercitivas) ou não punitivas (indutivas) (Gotzens, 2003; Kaplan, 1992; Sugai \& Horner, 2002). 
Os problemas de comportamento tendem a ser os quadros disfuncionais mais comuns associados à utilização de determinadas práticas educativas, pois evidenciam as dificuldades das crianças na construção e manutenção de relações sociais/interpessoais. Essas dificuldades comportamentais infantis mostram-se interdependentes das práticas educativas, reiterando a reciprocidade das relações parentais e educativas (Alvarenga \& Piccinini, 2001; Belsky \& cols., 2001; Collins \& cols., 2000; Stollmiller, 2001).

Tanto frente aos quadros de problemas de comportamento, como na sua ausência, entendemos que estas práticas não se constituem num todo homogêneo. Pelo contrário, a sua utilização varia ao longo do tempo de acordo com as experiências da família, suas crenças, conhecimentos, idade, condições de vida, ideias, configurando cada família como um microsistema distinto, que se modifica no tempo e no espaço em que está inserido, assim como a escola (Tornaría, Valdemeulebroecke, \& Colpin, 2001; Viana, 2005; Vila, 2003).

Como os problemas de comportamento evidenciam a existência de falhas, tanto em relação às práticas educativas da família como da escola frente à socialização, parece-nos importante a troca de informações e busca de ações conjuntas família-escola. A partir de tais considerações teóricas, este estudo pretende conhecer e comparar as práticas educativas utilizadas por pais e professoras de crianças em idade escolar que apresentam problemas de comportamento na escola, analisando possíveis continuidades e descontinuidades na relação entre esses dois sistemas. O estudo buscou também investigar a existência de atividades conjuntas que revelam facilidades e dificuldades nas interações família-escola.

\section{Método}

\section{Participantes}

Participaram do estudo quatro pais (três mães e um pai) e quatro professoras de crianças, entre 7 e 11 anos de idade, que apresentavam problemas de comportamento na escola. As crianças foram indicadas pelo SOE (Serviço de Orientação Educacional) das escolas, entendendo os problemas de comportamento como dificuldades de relacionamento/socialização de tais crianças. Os pais possuíam entre 33 e 42 anos, sendo uma das famílias monoparental (gerenciada pelo pai), uma cuja mãe é casada pela segunda vez e outras duas originais. Dentre as professoras, a experiência profissional variou entre 7 e 19 anos de magistério, sendo que todas atuavam em escolas confessionais de grande porte da rede privada da cidade de Porto Alegre, atendendo a um público de nível socioeconômico médio.

\section{Instrumentos}

Foram realizadas duas entrevistas com cada um dos participantes. A primeira, uma entrevista dirigida, questionava-os a respeito das práticas educativas utilizadas em 12 situações específicas (como, por exemplo, ignorar e desobedecer regras, agredir outros etc.). Para a construção da entrevista, identificou-se, na literatura nacional e internacional, indicadores de problemas de comportamento utilizados em estudos anteriores, tanto qualitativos como quantitativos (Silveira, 2005). Criou-se, então, um dilema situacional para cada um dos comportamentos levantados, tanto para pais como para professores, testados e aprovados num estudo piloto (Silveira, 2005). A segunda entrevista, semidirigida, investigou dois temas: 1) a percepção dos pais (família) a respeito das práticas educativas utilizadas pelas professoras (escola) e vice-versa; e 2) a existência de ações conjuntas pais-professoras (família-escola) frente às dificuldades da criança.

\section{Procedimentos de coleta dos dados}

Os profissionais do Serviço de Orientação Educacional (SOE) das escolas indicaram casos de alunos com problemas de comportamento e agendaram as entrevistas. Todos os participantes assinaram o Termo de Consentimento Livre e Esclarecido depois de informados sobre o estudo e esclarecidas as suas possíveis dúvidas.

\section{Procedimentos de Análise dos dados}

Foi realizada uma análise de conteúdo das entrevistas segundo o referencial de Olabuénaga (1999). A partir da primeira entrevista, classificamos e comparamos as práticas educativas dos participantes de acordo com sua orientação, definida a priori: indutiva, coercitiva, ou não interveniente (Alvarenga \& Piccinini, 2001; Silveira, 2005). Já a análise da segunda entrevista baseou-se em dois eixos temáticos, definidos a priori. O primeiro eixo tratou da Percepção quanto à utilização das práticas educativas (tanto dos pais em relação às professoras, como das professoras em relação aos pais) e o segundo eixo de análise contemplou o Planejamento de ações conjuntas famíliaescola. Em cada eixo, foram categorizadas as respostas de pais e professoras separadamente. Tal categorização foi construída a posteriori, conforme referencial metodológico de Olabuénaga (1999). Tal referencial permite a criação de eixos temáticos das categorias evidenciadas, bem como postula que a criação de suas categorias não necessita seguir o critério de "excludência" (como em outros métodos de análise de conteúdo), promovendo a interdependência de eixos e categorias para a discussão dos dados.

\section{Apresentação dos Resultados}

A Tabela 1 apresenta os resultados referentes às práticas educativas utilizadas no contexto escolar e familiar frente às doze situações investigadas, evidenciando que pais e professores empregam tanto práticas educativas indutivas como coercitivas.

Observamos que, no contexto familiar, os pais revelaram utilizar-se tanto de práticas indutivas como coercitivas frente às situações investigadas com seus filhos. Já as professoras empregaram, nas mesmas situações, mais vezes, exclusivamente, práticas indutivas do que 
Tabela 1. Distribuição das práticas educativas utilizadas pela família e pela escola

\begin{tabular}{|l|c|c|c|c|c|c|}
\hline \multirow{2}{*}{$\begin{array}{l}\text { Situações apresentadas para a } \\
\text { família e para a escola }\end{array}$} & \multicolumn{2}{|c|}{$\begin{array}{r}\text { Tipo de prática utilizada } \\
\text { na família }\end{array}$} & \multicolumn{3}{|c|}{$\begin{array}{r}\text { Tipo de prática utilizada na } \\
\text { escola }\end{array}$} \\
\cline { 2 - 8 } & $\mathrm{I}$ & $\mathrm{C}$ & $\mathrm{NI}$ & $\mathrm{I}$ & $\mathrm{C}$ & $\mathrm{NI}$ \\
\hline $\begin{array}{l}\text { 1. ofende uma criança/amigo, usan- } \\
\text { do um apelido depreciativo }\end{array}$ & $\mathrm{X}$ & $\mathrm{X}$ & $\mathrm{X}$ & $\mathrm{X}$ & $\mathrm{X}$ & \\
\hline $\begin{array}{l}\text { 2. responde de forma rude, grossei- } \\
\text { ra, sendo mal-educado(a) }\end{array}$ & $\mathrm{X}$ & $\mathrm{X}$ & $\mathrm{X}$ & $\mathrm{X}$ & & \\
\hline $\begin{array}{l}\text { 3. agride ou machuca outras crian- } \\
\text { ças }\end{array}$ & $\mathrm{X}$ & $\mathrm{X}$ & & $\mathrm{X}$ & $\mathrm{X}$ & \\
\hline $\begin{array}{l}\text { 4. pega algo dos outros sem per- } \\
\text { missão }\end{array}$ & $\mathrm{X}$ & $\mathrm{X}$ & & $\mathrm{X}$ & & \\
\hline $\begin{array}{l}\text { 5. recusa-se a dormir ou a cumprir } \\
\text { algo da rotina }\end{array}$ & $\mathrm{X}$ & $\mathrm{X}$ & & $\mathrm{X}$ & & $\mathrm{X}$ \\
\hline $\begin{array}{l}\text { 6. desobedece ou ignora as regras } \\
\text { ou instruções dos pais/professora }\end{array}$ & $\mathrm{X}$ & $\mathrm{X}$ & & $\mathrm{X}$ & $\mathrm{X}$ & \\
\hline 7. mente & $\mathrm{X}$ & $\mathrm{X}$ & $\mathrm{X}$ & $\mathrm{X}$ & $\mathrm{X}$ & $\mathrm{X}$ \\
\hline 8. implica, incomoda & $\mathrm{X}$ & $\mathrm{X}$ & $\mathrm{X}$ & $\mathrm{X}$ & & $\mathrm{X}$ \\
\hline 9. estraga algo dos outros & $\mathrm{X}$ & $\mathrm{X}$ & & $\mathrm{X}$ & $\mathrm{X}$ & \\
\hline 10. cria problemas & $\mathrm{X}$ & $\mathrm{X}$ & $\mathrm{X}$ & $\mathrm{X}$ & $\mathrm{X}$ & \\
\hline 11. fica mal-humorada e nervosa & $\mathrm{X}$ & $\mathrm{X}$ & $\mathrm{X}$ & $\mathrm{X}$ & $\mathrm{X}$ & \\
\hline $\begin{array}{l}\text { 12. não é muito querida pelas ou- } \\
\text { tras crianças }\end{array}$ & $\mathrm{X}$ & $\mathrm{X}$ & $\mathrm{X}$ & $\mathrm{X}$ & $\mathrm{X}$ & \\
\hline $\begin{array}{l}\text { TOTAL DAS PRÁTICAS UTLIZA- } \\
\text { DAS }\end{array}$ & 12 & 12 & 6 & 12 & 7 & 3 \\
\hline
\end{tabular}

$\mathrm{I}=$ práticas indutivas; $\mathrm{C}=$ práticas coercitivas; $\mathrm{NI}=$ não interfere

Fonte: Elaborado pelas autoras

coercitivas, em comparação aos pais. Entretanto, ambos os sistemas apresentam uso combinado de práticas coercitivas e indutivas, o que nos leva a pensar que o uso exclusivo de uma ou de outra nas situações propostas tende a ser ineficaz. No entanto, tratando-se de crianças com problemas de comportamento, pode-se pensar que nem mesmo a combinação de tais práticas mostre-se eficaz. Na família, porém, a heterogeneidade das práticas educativas foi presente em todas as situações, o que não se evidenciou no contexto escolar. Evidenciou-se também maior frequência de respostas das mães/pais "não interferirem" em situaçõesproblema, especialmente nas situações 1, 2, 11 e 12 (que supõem ofensa, agressão, mau-humor da criança e ser evitada pelos colegas). Entendeu-se que estas respostas podem associar-se ao fato de tais situações tornarem mais explícitas as dificuldades da criança. A partir da exposição dos resultados, observamos uma diferença importante no que se refere à utilização das práticas educativas no contexto escolar e familiar.

A partir da análise qualitativa das respostas dos participantes às questões do eixo 1 , que diz respeito à percepção quanto à utilização das práticas educativas, tanto dos pais em relação às professoras, como delas em relação aos pais, evidenciamos as categorias a seguir. A análise das respostas das professoras gerou quatro categorias: parentalidade invertida, uso de regras, comunicação entre o casal e atividade da família em conjunto; enquanto a análise das respostas dos progenitores gerou cinco categorias: desconhecimento, não interferência, confiar, negociar e exercer autoridade. 
A respeito do conhecimento das professoras sobre situações familiares semelhantes às dificuldades comportamentais que a criança apresenta na escola, as falas revelaram que apenas uma das professoras não soube relatar tais situações. A partir da descrição de situações como desrespeitar ou ignorar as ordens dos pais, implicar com irmã(o)s, responder grosseiramente aos pais, entre outras, as professoras descreveram sua percepção quanto às práticas educativas parentais (Eixo 1), apontando as falhas na educação familiar, segundo suas ideias.

A primeira categoria revela que as professoras observam, por vezes, uma parentalidade invertida, descrevendo a ideia de que os pais são submetidos aos filhos, ao invés do contrário. Elas acreditam que a criança tenha "liberdade demais..." (profa. 3), ou ainda "comanda muito essa família" (profa. 4). Nesse sentido, apontam a necessidade de resgatar o uso de regras pelas mães, dando limites mais claros aos filhos, como, por exemplo: "pai e mãe têm que ter regras claras, que nem a gente tem combinações em sala de aula" (profa. 4). Além destas questões familiares, as professoras também identificam dificuldades que se referem à comunicação entre o casal, sinalizando que "eles tinham que se comunicar mais entre eles... e assim dar um norte" (profa. 1). Conforme as falas das mesmas, há também a necessidade de atividades da família em conjunto, que os pais proporcionassem "uma atividade que todos participem" (profa. 3).

A análise das respostas dos pais revelou que todos sabiam da ocorrência de situações-problema na escola, evidenciando conhecimento sobre o problema de comportamento de seu(sua) filho(a). A partir da descrição de situações como não cumprir ordens da professora/escola, não realizar as atividades propostas, bater e implicar com os colegas, os pais foram questionados sobre sua percepção quanto à utilização das práticas educativas no contexto escolar.

Diferentemente das professoras, os pais pouco criticaramaconduta das professorase inclusiveseausentaram dessa avaliação ou delegaram mais responsabilidades a elas e à escola. Os pais referiram desconhecimento a respeito das práticas educativas utilizadas pelas professoras, pois, para todos, a professora "não me explicou muito" (mãe 1), ou ainda "nem sei te dizer" (mãe 4). De forma semelhante, a opinião sobre como acreditam que as professores deveriam agir com seus filhos destacou o conteúdo de não interferência: "a professora sabe porque estudou... tem que saber como lidar... Eu não me preocupo com professor, parto do princípio que o professor sabe como lidar" (pai 2).

Em função de tal desconhecimento sobre o que acontece em sala de aula, os pais relatam a importância de confiar na escola, como, por exemplo: "confio na professora e cuido dos meus filhos" (pai 2), pontuando a divisão de papéis. Os pais relataram também que as professoras deveriam, assim como eles, negociar com as crianças: "Tem que negociar com ela, como eu negocio" (pai 2). De forma semelhante, expressaram sua vontade de que as professoras pudessem exercer sua autoridade, dando castigos, sendo rígidas etc.: "Tiram coisas com meu aval" (mãe 4).
As categorias construídas com as respostas de pais e professoras a respeito do planejamento de ações conjuntas entre a família e a escola (Eixo 2) frente às dificuldades da criança também foram feitas separadamente. Conforme a análise das respostas das professoras, foram construídas seis categorias: encaminhamento, buscar a criança, comprometimento da professora e omissão da família, participação das psicólogas, organização de materiais e acompanhamento das tarefas e a família agradece à escola. Seguindo a análise das respostas dos pais, foram geradas quatro categorias: encaminhamento, mudanças estruturais, indicação e acompanhamento de atividades, e ajuda, todas perpassadas por duas outras categorias: reuniões e culpa da família.

Nas entrevistas com as professoras, descreveram o encaminhamento da criança a uma avaliação/atendimento psicológico como uma atitude integradora entre a família e a escola. Outra atitude de integração família-escola descrita pelas professoras foi a de buscar a criança quando apresentar mau comportamento, ou seja, os pais precisaram retirar a criança da escola por um tempo: "Nesses momentos que ele saía da sala os pais vinham buscá-lo, essa foi a combinação" (profa . 1). As professoras também descreveram combinações nas quais elas se comprometeram/incluíram conteúdos em seu trabalho como "estratégias" para lidar com os problemas de comportamento das crianças, ao passo que as famílias se omitiram de relatar as práticas educativas utilizadas (comprometimento da professora e omissão da família), como na fala: "ela nunca coloca o que vai ser feito para modificar a situação... Ficou a combinação do que eu faria aqui na escola, e o que ela vai fazer em casa, ele não colocou" (profa. 3).

Identificamos também que, por vezes, tais combinações não eram realizadas diretamente com a família, mas sim através da participação das psicólogas que atendiam esses alunos: "só [combinamos] através do atendimento com a psicóloga e aqui na escola" (profa ${ }^{a}$ 2). Outra estratégia descrita pelas professoras refere-se à organização de materiais e acompanhamento de tarefas por parte da família, porém com um caráter de "ordem": "Ele tem que estar com os materiais organizados na mochila, as folhas coladas.. É uma combinação que fizemos com essa mãe, que ela ajudasse nisso" (profa. 4). Ainda, conforme os relatos das professoras, a família agradece à escola, especialmente no que diz respeito às orientações da escola: "a mãe diz: 'eu sei que é difícil e tudo'... a família está do nosso lado" (profa. 1).

Através da análise das respostas dos pais, destacamos duas categorias que perpassam as ações conjuntas família-escola: a existência de reuniões e a "culpa da família". Anteriormente ao planejamento de ações conjuntas, são bastante frequentes as reuniões na escola para tratarem do problema de comportamento do(a) filho(a), como comentaram: "Desde março eu já conheço todos os psicólogos..." (mãe 1). Sobre esses encontros, destacamos também as ideias que os pais relataram acerca das explicações que a escola apresenta a respeito das 
causas familiares para os problemas da criança, referindo à "culpa da família", "Imaginava que os professores estavam imaginando aquilo: o caos na família” (mãe 1).

Quanto às falas dos pais, especificamente a respeito do planejamento de ações conjuntas com a escola frente às dificuldades da criança, eles apontaram que estas combinações eram mudanças estruturais, pois envolveram a estrutura e organização da rotina familiar: "para nós foi uma mudança estrutural... ele estava no turno integral e achamos (junto às reuniões com a escola) melhor ele sair" (mãe 1). Os pais também identificaram o encaminhamento da criança a um atendimento psicológico como uma combinação entre a família e a escola: "... elas falaram que ela era muito agitada e aí ela começou a frequentar a $A$ (psicóloga)... Elas sugeriram..." (pai 2).

A indicação e acompanhamento de atividades extras às crianças também foi mencionada como uma combinação entre a família e a escola: "fiz uma combinação com ela que mandasse atividade extra quando ele não fizesse na aula" (mãe 3). Tratando dessas combinações, identificamos uma categoria de respostas chamada "ajuda", na qual agrupamos as respostas que indicaram que os pais valorizaram e contaram com a ajuda da escola. Como o pai $2 \mathrm{diz:}$ "venho aqui e digo: 'vocês tem que me ajudar, tem o SOE, são profissionais... Tem que ajudar os pais mais do que os pais ajudar os professores'”, remetendo à ideia de que a escola é mais instrumentalizada para ajudar os pais a educarem seus filhos. Num sentido "aparentemente" oposto, a mãe 4 afirma que "tudo que for para auxiliar eu estou pronta. Para mim não tem problema...", fazendo-nos pensar que a família é que está ajudando a escola.

\section{Discussão dos Resultados e Considerações Finais}

Os resultados apresentados nos permitem uma reflexão sobre como está construída a interação família-escola quando a criança apresenta problema de comportamento. Os achados evidenciam certa continuidade entre as práticas educativas parentais e escolares de caráter indutivo, porém revelam importantes lacunas a respeito de como as professoras/escolas e as famílias têm se comunicado e buscado agir de forma conjunta frente às dificuldades comportamentais das crianças.

Quanto à utilização das práticas educativas pela família e pela escola, parece-nos importante destacar a heterogeneidade das mesmas, especialmente nas famílias. Os pais revelaram utilizar práticas educativas coercitivas e indutivas com a mesma frequência, sem que possamos destacar grandes diferenças entre o uso destas. Estes dados parecem reiterar a afirmação de que as práticas educativas tendem a ser heterogêneas, respeitando a existência de múltiplas variáveis associadas ao contexto e àquele que as aplica (Dabas, 2005; Tornaría \& cols., 2001; Vila 2003). Com isso, reafirma-se a necessidade de compreender as práticas educativas inseridas num contexto específico, levando em consideração as múltiplas variáveis associadas a seu emprego (Bélsky, 1984; Collins \& cols., 2000).

A heterogeneidade na utilização das práticas educativas pode também se associar ao fato de que a ação dos professores, a sua formação profissional específica e o contexto legal da escola não permitem a utilização de muitas das práticas coercitivas. Nesse sentido, as práticas educativas na escola podem ser reforçadas pelas regras e combinações da sala e da escola, elemento bastante referido pelas professoras e que pareceu robustecer a eficácia das mesmas. De certa forma, podemos corroborar a ideia de que as práticas coercitivas e os problemas de comportamento na infância são elementos vinculados, tanto pela presença de tais práticas educativas, como pela tímida prevalência das práticas indutivas. Pensamos também que, em função da entrevista ter sido realizada na escola, alguns dados em relação a este aspecto podem ter sido enviesados, já que a utilização de práticas predominantemente indutivas é considerada politicamente correta.

Sabe-se, também, que muitas informações a respeito da educação de crianças e adolescentes têm circulado na mídia e se tornado senso comum, intimidando os pais a revelarem o uso daquelas práticas educativas conhecidamente contraindicadas e, até mesmo, proibidas (já que a punição física foi proibida no Estatuto da Criança e do Adolescente [Conselho Municipal dos Direitos da criança e do adolescente, 1994]). A quantidade de informação disponível atualmente sobre a educação de crianças parece, paradoxalmente, facilitar e ao mesmo tempo assustar os pais a respeito de como educar seus filhos. Dessa forma, observamos que, embora os pais possuam muitas informações que orientam o que devem ou não fazer, este é um aspecto que parece não garantir que eles "façam" ou "não façam" o que é prescrito. Nesse caso, observa-se que a informação por si só não é suficiente, sendo necessário incluir outras variáveis na orientação dos pais em relação ao manejo com seus filhos. Desenvolver a empatia e a sensibilidade para as necessidades da criança são alguns dos aspectos essenciais nesse processo.

Quanto ao conhecimento de situações semelhantes na escola e/ou família, algumas descontinuidades ficaram evidentes. Chamou-nos a atenção, especialmente, o desconhecimento dos pais a respeito de como as professoras agem com seus filhos em situações difíceis. Ao mesmo tempo, eles comentaram confiar no trabalho das professoras e assim não julgam nem buscam interferir no trabalho das mesmas. Esse dado contrapõe-se ao que é descrito em estudos anteriores (Chechia \& Andrade, 2005; Oliveira, 2002), nos quais as autoras descrevem que os pais tendem a se mostrar descontentes com o afastamento da escola, mostrando-se fiscalizadores das ações dos professores e evidenciando sentimentos de desconfiança e ciúmes. Compreendemos também que estas ideias podem se apoiar no que referem Carvalho (2004) e Viana (2005) sobre a falta de participação dos pais na escola por aceitarem o saber "dos especialistas" como superior. Podemos questionar também: 
como eles confiam no que não conhecem? Acreditamos que, talvez pelo senso comum e pelas ideias perpetuadas a respeito do saber da escola, esta assuma tal supremacia, fazendo com que os pais não questionem e confiem nas suas práticas.

Ainda a respeito da falta de conhecimento dos pais, evidenciamos que este dado pode apoiar-se no estudo de Vila (2003), que destaca a intenção dos professores em "ensinar" os pais a educarem melhor seus filhos, fornecendo-lhes informações e conhecimentos a respeito. A esse respeito, em nosso estudo, observamos que as professoras prontamente apontaram dificuldades familiares e de exercício da função parental quando questionadas sobre as ações educativas dos pais de seus alunos. Através das categorias analisadas, notamos que as professoras tendem a criticar negativamente o manejo das famílias.

Talvez, em função disso, os pais queiram assegurarse desse papel da escola quando referem "não interferir" nas práticas educativas das professoras, julgando que elas deveriam "exercer a autoridade" com seus filhos. Nesse caso, os pais posicionam-se de forma a distanciar e delimitar papéis claros para a escola, quando revelam que não "querem" interferir na ação educativa das professoras e assim reafirmam a "autoridade" das mesmas. Parece-nos clara a existência de uma rígida fronteira entre o sistema escolar e familiar, distinguindo seus saberes e, consequentemente, suas funções educativas, que parece incluir a educação familiar. Assim, podemos questionar: será que essa autoridade faz(ia) parte de suas funções educativas, que foram tomadas ou entregues à escola e às professoras como consequência desta "soberania" do saber escolar? Parece-nos que a escola e a família buscam realizar ações para definir responsabilidades na educação das crianças, ao invés de realmente uniremse e cooperarem nessa tarefa. Mas será realmente possível construir um modelo cooperativo sem permeabilidade entre as fronteiras e sem alterar alguns elementos dos sistemas? Acreditamos que é necessário que as fronteiras tornem-se menos rígidas, o que será possível a partir da (re)definição das tarefas educativas de cada sistema, para que se efetive a ideia de cooperação.

Ainda sobre descontinuidades nas interações família-escola, as professoras e os pais identificaram como ações conjuntas algumas "tarefas" delegadas aos pais. As categorias descritas como: encaminhamento, atividades extras, buscar a criança quando apresentar mau comportamento e organização e acompanhamento de tarefas remetem a exigências do quê e como a família deve "ajudar" nesse processo. Compreendemos que, novamente, a escola pareceu ter o "controle" e delegou "orientações" e 'encaminhamentos' às famílias, pouco se comprometendo com estas. Tanto os pais como as professoras não revelaram que a escola se comprometeu com novas atitudes ou com mudanças a respeito de suas ações frente às dificuldades das crianças, o que parece muito necessário (Chechia \& Andrade, 2005; Carvalho, 2004; Davis \& Lambie, 2005).

Nesse sentido, pais e professores relatam que a escola ajuda a família, o que parece reforçar as ideias a respeito dos movimentos da primeira em estabelecer seu saber como superior à família (Carvalho, 2004; Ditrano \& Silverstein, 2006; Kumar, 2006; Marchesi, 2006; Viana, 2005). A ideia de que a escola supre melhor a função de cuidado das crianças, revelando que a família não é preparada tecnicamente para tal tarefa, parece ser corroborada entre estes participantes, ligando-se também à categoria "culpa da família". Nesta, observamos que os pais entrevistados têm consciência de que as professoras associam os problemas de comportamento da criança às práticas familiares. Sobre isso, estudos recentes (Chechia \& Andrade, 2005; Oliveira, 2002) descrevem que tal ideia é frequente e tende a afastar os pais da escola e dificultar a comunicação entre ambos.

As atividades relatadas com o intuito de promover a interação família-escola aparecem através da organização de materiais e acompanhamento de tarefas. Com estas, a escola proporciona aos pais uma forma de participação indireta sobre a sala de aula, fazendo com que eles acompanhem o desenvolvimento das crianças, supervisionando-as. Tal fato tem sido destacado como preditor de sucesso escolar e de maior proximidade na relação família-escola (Carvalho, 2004; Chechia \& Andrade, 2005; Viana, 2005). Já a prática de buscar a criança quando apresentar mau comportamento na escola pode tanto destacar a participação dos pais na vida escolar do filho como apresentar um caráter negativo, punitivo, evidenciando que a família só é chamada quando não funcionam as estratégias educativas escolares.

Identificamos também dificuldades frente à interação das escolas em relação à pesquisadora, relativas à "inserção ecológica" desta (termo utilizado por Koller, 2004). Dentre dez escolas contatadas, apenas três autorizaram e viabilizaram a investigação. Quando se fazia o contato inicial e relatavase o tema da investigação, as instituições mostravam-se interessadas e revelavam que o quadro de problemas de comportamento era frequente. No entanto, ao se evidenciar a necessidade de entrevistar os pais, outros "problemas" começavam. Para estas escolas, contatar as famílias (e nos pareceu que a dificuldade era de "contar") seria muito complicado, e surgiriam dificuldades em explicar aos pais "por que seu filho e não outros".

Essas informações foram inquietantes desde o início do estudo e, a cada negativa, reiterava-se a necessidade de considerá-las como parte importante da pesquisa. Parece-nos que estas condutas evidenciam, mais uma vez, a dificuldade existente quanto à interação famíliaescola frente aos problemas de comportamento da criança. Compreendemos que, frente às dificuldades mencionadas, certamente estes pais não eram cientes do problema que seu filho apresentava na escola. Parece-nos que, nessas escolas, a relação estabelecida com a família era de certa forma "superficial", evitando desgastes e desafios que exigissem mais de cada uma das partes. Podemos pensar também que, nessas escolas recusantes, as fronteiras estivessem demasiadamente rígidas, semelhante ao evidenciado nos dados, a ponto de não haver a possibilidade de intersecção entre os sistemas, mesmo em prol do desenvolvimento saudável das crianças. 
Nesse trabalho, pudemos constatar que existem importantes diferenças entre os sistemas escolar e familiar, entretanto é factível a interdependência entre os contextos, o que exige espaços de intersecção onde se criem possibilidades de complementaridade entre eles. Carece-se de pesquisas acerca da interdependência entre sistemas, transpondo um modelo linear e individual. Parece-nos fundamental a realização de estudos com vistas a construir e propor um modelo de integração entre os sistemas, favorecendo o conhecimento das ações e funções educativas de ambos e construindo novas formas de comunicação e interação entre a família e a escola.

\section{Referências}

Alvarenga, P. (2000). Práticas educativas maternas e problemas de comportamento na infância. Dissertação de Mestrado, Instituto de Psicologia da Universidade Federal do Rio Grande do Sul, Porto Alegre, Rio Grande do Sul.

Alvarenga, P., \& Piccinini, C. A. (2001). Práticas Educativas e problemas de comportamento em Pré-escolares. Psicologia: Reflexão e Crítica, 14(3), 449-460.

Belsky, J. (1984). The determinants of parenting: A process model. Child Development, 55, 83-96.

Belsky, J., Jaffee, S., Hsieh, K., \& Silva, P. A. (2001). Child-rearing antecedents of intergenerational relations in young adulthood: A Prospective study. Developmental Psychology, 37(6), 801-813.

Bolsoni-Silva, A. T., \& Marturano, E. M. (2002). Práticas educativas e problemas de comportamento: Uma análise à luz das habilidades sociais. Estudos de Psicologia, 7(2), 227-235.

Carvalho, M. E. P. de. (2004). Modos de educação, gênero e relações escola-família. Cadernos de Pesquisa, 34(121), 41-58.

Ceballos E., \& Rodrigo, M. J. (2003). Las metas y estrategias de socialización entre padres e hijos. Em M. J. Rodrigo \& J. Palacios (Coords.), Familia y desarrollo humano (4a ed., pp. 225-244). Madrid: Alianza Editorial.

Chechia, V. A., \& Andrade, A. dos S. (2005). O desempenho escolar dos filhos na percepção de pais de alunos com sucesso e insucesso escolar. Estudos de Psicologia, 10(3), 431-440.

Collins, W. A., Maccoby, E. E., Steinberg, L., Hetherington, E. M., \& Bornstein, M. H. (2000). Contemporary research on parenting: The case of nature and nurture. American Psychologist, 55(2), 218-232.

Conselho Municipal dos Direitos da Criança e do Adolescente. (1994). ECA - Estatuto da Criança e do Adolescente. Prefeitura de Porto Alegre.

Dabas, E. (2005). Redes Sociales, familias y escuela (2a reimp.). Buenos Aires : Paidós.

Davis, K. M., \& Lambie, G. W. (2005). Family engagement: A Collaborative, systemic approach for middle school counselors. Professional School Counseling, 9(2), 144-151.

Ditrano, C. J., \& Silverstein, L. B. (2006). Listening to parents' voices: Participatory action research in the schools. Professional Psychology: Research and Practice, 37(4), 359-366.

Dowling, E. (1996). Marco teórico: Um enfoque sistémico conjunto de los problemas educativos com niños. Em E. Dowling \& E. Osborne (Orgs.), Família y Escuela: Una aproximación conjunta y sistémica a los problemas infantiles (pp.21-50). Buenos Aires: Paidós.
Ferreira, F. de C., \& Marturano, E. M. (2002). Ambiente familiar e os problemas de comportamento apresentados por crianças com baixo desempenho escolar. Psicologia: Reflexão e Crítica, 15(1), 35-44.

Goldwater, O. D., \& Nutt, R. L. (1999). Teachers' and students' work-culture variables associated with positive school outcome. Adolescence, 34(36), 653-664.

Gotznes, C. (2003). A disciplina escolar: prevenção e intervenção nos problemas de comportamento ( $\mathrm{F}$. Murad, Trad.). Porto Alegre: Artmed

Harvey, D. (1989). A condição pós-moderna. São Paulo: Loyola.

Hoffman, M. L. (1975). Moral internalization, parental power, ad the nature of parent-child interaction. Developmental Psychology, 11(2), 228-239.

Hoffman, M. L. (1994). Discipline and Internalization. Developmental Psychology, 30(1), pp. 26-28.

Johnsons, L. J., Pugach, M. C., \& Hawkins, A. (2004). School-family collaboration: A Partnership. Focus on exceptional children, $36(5), 1-12$

Kaplan, C. (1992). Teacher's punishment histories and their selection of disciplinary strategies. Contemporary Educational Psychology, $15,258-265$

Koller, S. H. (2004). Ecologia do desenvolvimento humano. São Paulo: Casa do Psicólogo.

Kumar, R. (2006). Student's experiences of home-school dissonance: The role of school academic culture and perceptions of classroom goal structures. Contemporary Educational Psychology, 31, 253-279.

Marchesi, A. (2006). A família, entre o desalento e a despreocupação. Em A. Marchesi, O que será de nós, maus alunos? (pp. 137-158). Porto Alegre: Artmed

Olabuénaga, J. I. R. (1999). Metodología de la investigación cualitativa. Bilbao, Espanha: Universidad de Deusto.

Oliveira, L. de C. F. (2002). Escola e família numa rede de (dês) encontros: Um estudo das representações de pais e professores. São Paulo: Cabral Ed

Silveira, L. M. de O. B. (2003). A família, a escola e a (pós-) modernidade. Em P. A. Guareschi, A. Pizzinato, L. L. Krüger \& M. M. K. Macedo (Orgs.), Psicologia em questão: Reflexões sobre a contemporaneidade (pp. 123-132). Porto Alegre: EDIPUCRS

Silveira, L. M. de O. B. (2005). A interação família-escola frente aos problemas de comportamento da criança: Uma interação possível?. Projeto de Tese de Doutorado, Faculdade de Psicologia, Pontifícia Universidade Católica do Rio Grande do Sul, Porto Alegre - RS

Stollmiller, M. (2001). Synergistic interaction of child manageability problems and parent-discipline tatics in predicting future growth in externalizing behavior for boys. Developmental Psychology, $37(6), 814-825$.

Sugai, G., \& Horner, R. (2002). The evolution of discipline practices: School-wide positive behavior supports. Behavior Psychology in the Schools, 24(1/2), 23-50.

Tornaría, M. del L. G., Valdemeulebroecke, L., \& Colpin, H. (2001). Pedagogía Familiar: Aportes desde la teoría y la investigación. Montevideo: Ed. Trilce.

Viana, M. J. B. (2005). As práticas socializadoras familiares como lócus de constituição de disposições facilitadoras de longevidade escolar em meios populares. Educação e Sociedade, 26(90), 107-125.

Vila, I. (2003). Família y escuela : Dos contextos y um solo nino. In Alfonso et. al. (2003). La participación de los padres y madres en la escuela (pp. 27-38). Barcelona, Espanha: Editorial GRÀO. 
Recebido em: 24/12/2008

Reformulado em: 09/11/2009

Aprovado em: 10/12/2009

\section{Sobre as autores}

Luiza Maria de Oliveira Braga Silveira (luizasilveira@hotmail.com) Universidade Luterana do Brasil - Campus Gravataí.

Adriana Wagner (awagner@pucrs.br)

Pontifícia Universidade Católica do Rio Grande do Sul.

\section{Correspondência}

Luiza Maria de Oliveira Braga Silveira

Rua Goitacaz, 671 - Vila Assunção, POA/RS. CEP 91900-400.

Agradecimentos

Pesquisa apoiada pela CAPES. 